\title{
A discursividade sobre a universidade pública em períodos de crise democrática no Brasil (1964 / 2016)
}

\section{The discursiveness about the public university in periods of democratic crisis in Brazil (1964 / 2016)}

\section{La discursividad sobre la universidad pública en períodos de crisis democrática en brasil (1964 / 2016)}

\author{
iD Ana Paula Santos de Oliveira \\ Instituto Federal de Roraima (IFRR), Boa Vista, Roraima, Brasil. \\ E-mail: virtual.ana@gmail.com \\ iD Simone Natividade Santos \\ Instituto Federal de Alagoas (IFAL), Maceió, Alogoas, Brasil. \\ E-mail: simone.doutorado.sp@gmail.com
}

\begin{abstract}
Resumo: Este estudo transita pelo ambiente das universidades públicas brasileiras em dois momentos - no pós-golpe militar de 1964 e no pós-golpe institucional de 2016. O objetivo é compreender o funcionamento do discurso sobre a universidade em períodos de ameaça à democracia, quando, não por acaso, o sistema econômico pressiona os Estados a realizarem reformas em setores como educação e saúde. Assim, ancorada na Análise do Discurso de viés pecheutiano (PÊCHEUX, 2014; ORLANDI, 2012; SILVA SOBRINHO, 2018), o artigo se direciona para uma memória que é atualizada sempre que a classe hegemônica se vê ameaçada, levando ao avanço do autoritarismo estatal. Nesse contexto, a universidade pública, enquanto espaço de pluralidade de ideias e de resistência, é um dos principais alvos.
\end{abstract}

Palavras-chave: Memória. Universidade Pública. Estado. Resistência. 
Abstract: This study moves through the environment of Brazilian public universities in two periods of our republic - in the 1960s, after the military coup of 1964, and in the post-institutional coup in 2016. The objective is to understand the functioning of the discourse about the university in periods of strong threat to democracy, when, not by chance, the economic system pressures states to carry out reforms in sectors such as education and health. Thus, anchored in Discourse Analysis with a Pecheutian (PÊCHEUX, 2014; ORLANDI, 2012; SILVA SOBRINHO, 2018) bias, the article focuses on a memory that is updated whenever the hegemonic class is threatened, leading to the advance of state authoritarianism. In this context, the public university, as a space of plurality of ideas and resistance, is one of the main targets.

Keywords: Discourse. Memory. Public University. State.

Resumen: Este estudio transita por el ambiente de las universidades públicas brasileñas en dos períodos de nuestra república - en la década de 1960, después del golpe militar de 1964, y en el post-golpe institucional de 2016. El objetivo es comprender el funcionamiento del discurso sobre la universidad en períodos de fuerte amenaza a la democracia, cuando, no por casualidad, el sistema económico presiona a los Estados para que lleven a cabo reformas en sectores como la educación y la sanidad. Así, anclado en el Análisis del Discurso de sesgo pecheutiano (PÊCHEUX, 2014; ORLANDI, 2012; SILVA SOBRINHO, 2018), el artículo aborda una memoria que se actualiza cada vez que la clase hegemónica se ve amenazada, dando lugar al avance del autoritarismo estatal. En este contexto, la universidad pública, como espacio de pluralidad de ideas y resistencia, es uno de los principales objetivos.

Palabras clave: Discurso. Memoria. Universidad pública. Estado.

Submetido em 01 de abril de 2021.

Aceito em 04 de agosto de 2021.

Publicado em 06 de janeiro de 2022. 


\section{Introdução}

Ambientado em dois períodos da república brasileira - a ditadura militar (1964) e o pós-golpe de 2016 -, este artigo busca compreender o discurso sobre as universidades públicas brasileiras em momentos de crise democrática no país. Em nossas análises, partimos do arcabouço teórico da Análise de Discurso de filiação pecheutiana (AD) para desvelar os efeitos de sentido que atravessam dizeres que se contraidentificam em um cenário de crise estrutural do capital, evidenciada em desestabilização política em países subdesenvolvidos.

Assim, este estudo se direciona para a atualização de uma rede de sentidos que conduz à nossa formação como nação, de memórias que se cruzam e se ressignificam sob a determinação do modo de produção capitalista. Constituído de recortes que separam cerca de 50 anos da história recente do Brasil, seu corpus de pesquisa reúne dizeres que explicitam a ameaça do Estado à autonomia universitária, mas também indicam espaços de resistência ao avanço do autoritarismo estatal. Para as análises, mobilizamos categorias da AD, em especial as Condições de Produção, a Memória Discursiva e a Formação Discursiva, em diálogo com estudos marxistas. A seguir, delimitamos o nosso percurso teórico e sócio-histórico.

\section{A crise nas universidades na república em crise}

Em nosso gesto de interpretação, partimos das Condições de Produção (CPs), que "compreendem, fundamentalmente, os sujeitos falantes em constante relação com a cultura, a sociedade e a economia de um determinado momento histórico" (CAVALCAN$T E, 1999$, p. 151). Nessa perspectiva, as CPs convocam as posições discursivas, que se inscrevem, de acordo com Pêcheux (1988), na Formação Discursiva (FD), definida como 
Um romance hiper-circuitado: 2019 não passa e o curto da tradição literária Júlia de Mello Silva Oliveira • Nair Renata Amâncio • Rejane Cristina Rocha

aquilo que, numa formação ideológica dada, isto é, a partir de uma posição dada numa conjuntura dada, determinada pelo estado da luta de classes, determina o que pode e deve ser dito (articulado sob a forma de uma arenga, de um sermão, de um panfleto, de uma exposição, de um programa, etc.) (PÊCHEUX, 2014, p. 160).

De outro modo, o dizer está ligado às suas CPs e às posições a ele vinculadas. Sujeito e situação "são redefinidos discursivamente como partes das condições de produção do discurso", destaca Orlandi (1993, p. 110), que classifica a categoria em dois sentidos, a saber: estrito (ou imediato), que se relaciona às circunstâncias da enunciação, "o aqui e o agora do dizer", e o sentido amplo, que inclui o contexto sócio-histórico e ideológico.

Em sentido estrito, temos um corpus discursivo que remete a duas conjunturas, tão específicas quanto homogêneas. De um lado, temos um Brasil sob forte pressão do grande capital num contexto de Guerra Fria¹. De outro, temos um país novamente em crise, sob a determinação capitalista, ressignificada de neoliberalismo; sem a "ameaça" da Guerra Fria, mas, usando-se as mesmas armas ideológicas de outrora, como a criação de um inimigo político, que agora recai no ex-presidente Luiz Inácio Lula da Silva, do Partido dos Trabalhadores-PT, tachado de corrupto e com tendência comunista, assim como fizeram com ex-presidente João Goulart, do Partido Trabalhista Brasileiro-PTB, em 1964, fazendo ressurgir uma discursividade que no Brasil ganhou corpo no calor da revolução russa (1917).

Com os meios de comunicação da época refletindo o temor da classe econômica com a URSS, os jornais impressos reproduziam os dizeres de agências de notícias estrangeiras sobre o acontecimento. Desse modo, em lugar de usar termos como "revolução" e "revolucionários" para se referir ao evento de 1917 e a seus integrantes, usavam léxicos como "banditismo" e "subversão", associando o comunismo à imagem de inimigo da nação (MARIANI,

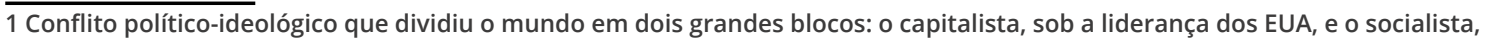
liderado pela ex-União Soviética. 
1998). Com isso, o Brasil começava a se adaptar às novas diretrizes das elites econômicas mundiais.

Em sentido amplo, tem-se um país que segue submisso às nações mais desenvolvidas economicamente desde que os primeiros portugueses chegaram aqui, mesmo após ter deixado de ser colônia (1815) e ter se emancipado politicamente (1822). Nesse sentido, o Brasil do pós-golpe de 2016 conserva a essência de 1964 - de país subdesenvolvido, determinado economicamente e ideologicamente pelas mesmas lideranças do mundo capitalista.

O nosso percurso de análise parte, pois, do discurso em seu processo sócio-histórico de constituição; de outro modo, como acontecimento afetado pela história. Considerando as CPs em estudo, Amaral (2005, p. 29) caracteriza esse processo como um “modo específico de produção e reprodução da sociedade capitalista", sustentada pelo antagonismo de classes.

Importante lembrar que, para funcionar, o sistema capitalista dispõe de setores que estão inseridos no dia a dia, em forma de religião, escola, família, justiça, política, sindicato, cultura e mídia. De acordo com Althusser (1985), esses setores, que englobam os Aparelhos Ideológicos do Estado (AIE), buscam regular, através de suas práticas e rituais, as ideias e os valores defendidos pela classe dominante, revelando a existência material da ideologia.

Partindo dessa perspectiva, Pêcheux (2014, p. 130) esclarece que cada uma das classes sociais não conta com a sua própria ideologia, como se cada uma vivesse "previamente à luta de classes". Os AIE são o lugar e meio de realização da ideologia dominante, afirma o autor, que ressalta que esses aparelhos são estabelecidos através da luta de classes. Logo, também constituem “o lugar e as condições ideológicas da transformação das relações de produção". 


\section{A educação como arma de controle econômico e social}

As tentativas de controle estatal sobre as universidades públicas ocorrem, não por acaso, com mais frequência em períodos de crise econômica, quando a educação pública, de modo geral, sofre com cortes orçamentários e com ameaças a sua liberdade de cátedra, muitas vezes mascaradas de reformas. Foi o que aconteceu em 1968, através da Lei $n^{\circ} 5.540 / 68$, que oficializou o acordo MEC-USAID². Com a justificativa de que o país precisava modernizar o seu sistema educacional, o acordo culminou em mudanças significativas em nosso ensino, como a retirada da grade curricular do ensino básico de disciplinas como Filosofia e Educação política e a oferta de Educação moral e cívica, com vistas ao controle do conhecimento.

Em forte ascensão, o autorismo estatal se fazia presente também no ensino superior, com os estudantes acusando o governo militar de crimes de lesa-pátria. Nesse sentido, Alves (1968) destaca que a intenção de transformar as universidades em fundações não apenas representava a restrição (já quase nula) de acesso dos filhos das classes mais baixas ao ensino superior, mas, sobretudo, a entrega do sistema universitário brasileiro aos interesses dos EUA.

A Reforma Universitária de 1968 revoltou ainda mais os estudantes, acirrando-se os conflitos com os militares. A bandeira da reforma - Modernização conservadora - fornece-nos marcas para entendermos a crise instalada no país na época, ao colocar, lado a lado, dois pré-construídos cujos sentidos se opõem, ao menos em aparência. Isso demonstra, conforme Pêcheux (2008, p. 53), que "todo enunciado é intrinsecamente suscetível de tornar-se outro".

Seguindo parâmetros autocráticos e privatizantes, a reforma universitária modificava a máquina educacional para conduzir a um maior controle da circulação de ideias pelo Estado militar, em especial as de teor marxista, comprometendo a autonomia uni-

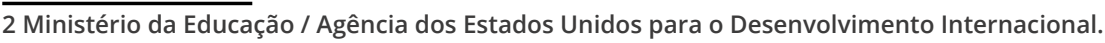


Um romance hiper-circuitado: 2019 não passa e o curto da tradição literária Júlia de Mello Silva Oliveira • Nair Renata Amâncio • Rejane Cristina Rocha

versitária. Para isso, foram criadas as Assessorias de Segurança e Informação (ASI), que coletavam informações em órgãos da administração indireta, autarquias e universidades para o governo militar.

Neste estudo, deparamo-nos com a atualização dessa memória cerca de 50 anos depois, materializada em ações que violam a autonomia universitária e em discursos de exaltação do regime militar. Essa atualização tem como marco inicial as "Jornadas de junho de 2013", como ficaram conhecidas as manifestações ocorridas em todo o Brasil, sobretudo contra o governo federal, culminando, três anos depois, em um golpe institucional que destituiu Dilma Rousseff (PT) da Presidência da República, sob a determinação do grande capital, sedento por reformas estruturais ${ }^{3}$, e na eleição de Jair Bolsonaro em 2018 - um saudosista da ditadura.

No campo educacional, o movimento "Escola sem partido" ganhou projeção nacional ao defender uma educação livre de ideologias em substituição ao que seus apoiadores nomeiam de doutrinação ideológica pelos professores. Enquanto isso, a extrema direita avançava no Brasil, às vésperas do golpe de 2016. Considerados inconstitucionais, os projetos de lei que tentam implementar as ideias do movimento nas escolas, como o PL n 867/15, ao evidenciar a defesa de uma educação apartidária, silenciam que, em verdade, não há sujeito sem ideologia (PÊCHEUX, 2014). O discurso tem uma relação necessária com o político, ou com as relações de poder, produzindo um efeito de evidência que busca convencer o interlocutor, levando-o a internalizar e reproduzir seus sentidos, esclarece Orlandi (2012).

Nas universidades públicas, o combate às "políticas ideológicas", como Jair Bolsonaro se refere às ideias que vincula à esquerda, toma forma em sua decisão de nomear reitores que não foram os mais votados por docentes, técnicos administrativos e alunos dessas instituições, privilegiando os candidatos alinhados ao seu governo, quebrando uma tradição respeitada nos governos de

3 Iniciadas pelo governo interino de Michel Temer (2016-2019), essas reformas têm como saldo ações alicerçadas em desconstruir direitos relativos à educação, ao trabalho e à previdência; esta última foi executada no governo do seu sucessor, Jair Bolsonaro (2019), de quem se espera a execução das reformas tributária e administrativa. 
FHC, Lula e Dilma Rousseff - de nomear os candidatos a reitores mais votados.

Junto a isso, ainda no primeiro ano do governo Bolsonaro, os recorrentes bloqueios e cortes nos orçamentos das universidades levaram as instituições a temerem o não pagamento de itens essenciais, como água e luz. Em maio de 2019, 5 mil bolsas da Coordenação de Aperfeiçoamento de Pessoal de Nível Superior (Capes), órgão que atua na expansão e consolidação da pós-graduação no país, foram cortadas. Como ato de resistência, estudantes foram às ruas para protestar contra os cortes e a desvalorização da ciência pelo governo (ALMEIDA, 2019).

Ao comparar a crise nas universidades brasileiras no pós-golpe de 1964 e no pós-golpe de 2016, observamos a atualização de uma discursividade que costuma circular quando a democracia já não representa um bem a ser preservado; quando o que se busca é, acima de tudo, explorar ainda mais a classe trabalhadora, penalizando a população mais vulnerável.

Trata-se de uma prática que vem se acentuando no século XXI, principalmente a partir da crise do capital iniciada em 2008 nos EUA, em que a democracia, mesmo nas economias desenvolvidas, não é mais vista pelos grupos dominantes como modelo político a ser seguido. É o que afirma Magalhães (2019, p. 82), ao destacar que o real da história demonstra esse fato a partir dos movimentos de trabalhadores da Europa, do caos na política dos EUA e do aumento da pobreza nos países subdesenvolvidos, "que apresentam uma democracia eleitoral e uma onda conservadora na cultura".

Considerando que todo discurso é produzido em CPs específicas, que, constitutivas do dizer, determinam o funcionamento do processo discursivo (PÊCHEUX, 2014), veremos, a seguir, como funciona a rede de memória sobre as universidades públicas brasileiras em tempos de crise democrática. Para isso, analisaremos um corpus constituído de materialidades discursivas que circularam no pós-golpe militar de 1964 e no pós-golpe de 2016. 


\section{O discurso sobre as universidades públicas em períodos de crise democrática}

Constituído de cinco sequências discursivas, o nosso corpus de análise se volta para diferentes momentos do Brasil republicano, que se cruzam ao evidenciarem acontecimentos que sinalizam a tentativa de implementação de uma agenda antidemocrática para o país, cujo reflexo atinge as universidades públicas enquanto espaços de pluralidade de ideias.

Para as nossas análises, fez-se necessário compreender como a educação é inserida no sistema capitalista. Nesse sentido, Duarte $(2006$, p. 6) aponta que, na perspectiva da classe hegemônica, a educação escolar precisa ser regulada e centrada no processo de produção da força de trabalho, "evitando-se a todo custo que o domínio do conhecimento venha a tornar-se um instrumento de luta por uma radical transformação das relações sociais de produção".

Mészáros (2011) vai além ao observar que a educação institucionalizada serve aos propósitos tanto de fornecer os conhecimentos e o pessoal necessário à máquina capitalista como de inculcar os valores da classe dominante desde os primeiros anos de escolarização, de modo a legitimá-los, como se não houvesse alternativa à gestão da sociedade.

Contudo, embora o Estado busque impor uma determinada forma de entender o mundo, na condição de sustentáculo do modo de produção vigente, outros sentidos derivam do campo educacional. É o que destaca Silva Sobrinho (2018), que, voltando-se para as universidades públicas, explica que, ainda que estas se ajustem à lógica capitalista, também podem se converter em espaços de resistência. Nesse sentido, o autor observa que:

A universidade está inserida no processo histórico, ou seja, possui caráter material e se entrelaça às polêmicas e práticas que movem, dialeticamente, a sociedade brasileira em seu processo histórico. Podemos dizer, por um lado, que a universidade tam- 
bém está sob o efeito da lógica do capital, e, por outro, também é lugar de resistência e revolta. (SILVA SOBRINHO, 2018, p. 611).

Partindo da concepção de língua em AD, que a vê como unidade aberta, relacionando-se com as suas condições de produção e com a sua exterioridade constitutiva (ORLANDI, 2012), entendemos que a resistência ao discurso hegemônico passa pelo caráter heterogêneo das Formações Discursivas (FDs), lugar de constituição dos sentidos que, em virtude de suas fronteiras fluidas são atravessadas por múltiplos sentidos, por elementos vindos de outras FDs, sempre apontando para a incompletude da linguagem. De outra forma, ainda que sofra a determinação de uma dada posição ideológica, o sujeito também é atravessado por discursos outros, com os quais se une e dos quais se diferencia (PÊCHEUX, 2014).

Nesse sentido, a análise das cinco materialidades relacionadas para este estudo indicou a existência de uma pluralidade de sentidos sobre a universidade, que ora busca cercear a sua autonomia, ora a posiciona como espaço de resistência ao retrocesso educacional.

Assim, três dias antes do segundo turno das eleições presidenciais de 2018, agentes dos Tribunais Regionais Eleitorais e da Polícia Federal, sob a alegação de supostas irregularidades eleitorais, fizeram buscas em pelo menos 27 universidades, onde retiraram faixas sem relação com a eleição, como uma faixa em homenagem à vereadora Marielle Franco, na Universidade Estadual do Rio de Janeiro, e com os dizeres "Direito UFF antifascista", na Universidade Federal Fluminense, entre outras, além de proibirem encontros envolvendo temáticas da ditadura militar e do fascismo, a exemplo do evento "Contra o fascismo, pela democracia", que seria realizado pela Universidade Federal do Rio Grande do Sul (DW, 2018).

Uma semana depois, o Supremo Tribunal Federal (STF) suspendeu as ações da Justiça Eleitoral. Em sua alegação, a ministra Cármen Lúcia tomou como fundamento o artigo $5^{\circ}$ da Constitui- 
ção Federal (CF/88), que estabelece a liberdade de manifestação de pensamento:

SD1 - A única força legitimada a invadir uma Universidade é a das ideias livres e plurais. Impedir ou dificultar a manifestação plural de pensamento é trancar a Universidade, silenciar estudantes e amordaçar professores. Qualquer outra ideia que ali ingresse sem causa jurídica válida é tirana, e tirania é o exato contrário da democracia (STF, 2018, grifo nosso).

Na sequência, vemos duas FDs que se contrapõem, sobressaindo-se a posição de defesa das universidades como espaço de livre circulação de ideias pela então presidente do STF, em sua atuação para a garantia da ordem institucional. A única força legitimada a invadir uma Universidade é a das ideias livres e plurais, afirma a ministra, indicando a existência de conflito entre dois órgãos do poder judiciário brasileiro quanto à abrangência do artigo $5^{\circ}$ da CF, o que reforça o caráter heterogêneo das FDs. Esse conflito é revelador do funcionamento dos Aparelhos Ideológicos do Estado, que agem no sentido de se ajustar aos interesses do sistema vigente, caso do Direito - sujeito a inúmeras interpretações.

Evidenciadas através de um discurso neutro e objetivo, suas práticas se direcionam, no Estado moderno, para os ideais de uma sociedade participativa, legitimados pela premissa de que todos são iguais perante a lei. Mas, o Direito não é isento de historicidade. Sua evidência se relaciona às formas das relações sociais de uma sociabilidade, adequando-se a elas. Para Sartori (2010), trata-se de práxis concreta, que nada tem de natural, neutra ou transcendental.

Dando continuidade à análise da SD1, Carmén Lúcia atribui, indiretamente, à justiça eleitoral a ação de tentar impedir ou dificultar a manifestação de ideias nas universidades para silenciar estudantes e amordaçar professores. A sua colocação atualiza 
uma memória que remete a períodos de exceção, a exemplo da ditadura militar brasileira, quando estudantes e professores universitários foram silenciados e amordaçados pela censura e pelo aparelho repressor estatal, quadro que demonstra que, em sua forma de imposição, o Estado funciona tanto ideologicamente como pela violência física; esta, sobretudo, quando aquela falha.

A ministra avança em sua colocação ao alertar que qualquer outra ideia que entre nas universidades sem validade legal é tirania, pré-construído que atualiza uma rede de memória ligada à opressão, crueldade e abuso de poder. Em geral, o tirano é representado como alguém que usa as forças repressivas do Estado contra seus opositores sob a justificativa de que assim declara guerra contra os "inimigos da nação", quando o que acaba gerando é uma guerra contra as liberdades civis. A tirania se filia, pois, ao discurso antidemocrático. É o que indica a ministra Cármen Lúcia quando afirma que a tirania é o exato contrário da democracia.

Contudo, a mesma fala silencia que nem sempre o STF agiu em favor da defesa da ordem institucional, a exemplo da posição que tomou por ocasião dos golpes de 1964 e 2016, ao não acusar a inconstitucionalidade da ruptura da ordem institucional no país (PRONER et al., 2016). A esse respeito, é válido retomar Mészáros (2011), que esclarece que a formação do Estado moderno é uma exigência para a manutenção da produtividade do capital, cuja dominação independe do modelo político adotado pelo Estado, se democrático ou totalitário, a exemplo da Alemanha nazista (19331945) e a ditadura de Pinochet (1973-1990), no Chile.

A próxima SD se soma à SD1 na constituição de uma rede de sentidos de defesa das universidades públicas brasileiras contra medidas antidemocráticas. Contudo, diferente do que ocorreu em 2018, a defesa das universidades evidenciada na SD2 não contou com o amparo dos poderes estatais encarregados de resguardar a pluralidade de ideias nessas instituições, quatro anos após o golpe. Logo, a SD2 funciona como espaço de resistência ainda maior. 


\section{SD2 - Universidade livre / Fora repressão}

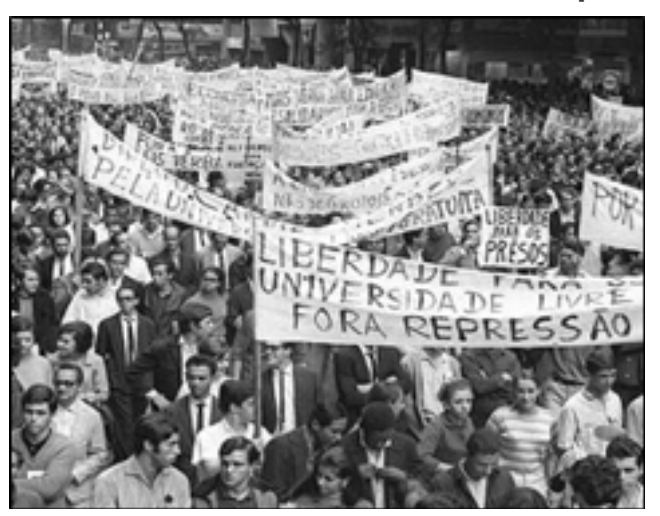

Fonte: Arquivo/Agência O Globo (1968).

Realizada em 26 de junho de 1968, na cidade do Rio de Janeiro, a Passeata dos cem mil, organizada pelo movimento estudantil, principal núcleo de oposição ao governo militar na época, reuniu, além de estudantes, professores, religiosos e populares. A multidão reivindicava o restabelecimento das liberdades democráticas, a suspensão da censura à imprensa e o repasse de mais verbas para o sistema educacional (FGV, 2009).

Na imagem do protesto, é possível observar, na faixa mais em destaque, os dizeres Universidade livre/fora repressão, que nos fornecem pistas para compreendermos a relação do Estado militar com as universidades públicas, que foi de conflito desde o início do regime, com as forças militares incendiando a sede da União Nacional dos Estudantes (UNE) em abril de 1964, nas primeiras horas após golpe, obrigando o movimento a atuar na clandestinidade.

Diferente da postura que adotou 50 anos depois, na ocasião o STF não agiu em favor da classe estudantil, calando-se frente à instalação da ditadura. A esse respeito, Carvalho (2017, p. 3) observa que, logo após o golpe, a regra no STF "era o silêncio sobre os efeitos políticos da ascensão do governo militar". Esse cenário reforça a essência dos AIE, que está atrelada à garantia do funcionamento do Estado, cujo fundamento se vincula à manutenção das relações de classes, independente do modelo político adotado, conforme Mészáros (2011). 
Em tempos de avanço do autoritarismo estatal, a violação da autonomia universitária começa com ataques sistemáticos de grupos ultraconservadores à circulação de ideias logo associadas à esquerda, como as voltadas para a defesa dos direitos humanos. A reprodução dessa discursividade foi essencial para os militares chegarem ao poder em 1964 e segue firme no imaginário do país. "O Brasil não será uma nova Cuba", "Justiça social sim, comunismo não", reproduziam alguns dos cartazes da Marcha da família com Deus pela liberdade, série de manifestações contra o governo Goulart e em favor dos militares realizadas no país em 1964. 50 anos depois, vemos a sua ressignificação em forma de "PT quer transformar o Brasil em país comunista", "Fora comunismo" circulando nas ruas do país desde 2013 (FGV, 2009).

Em março de 2019, disposto a recuperar o Brasil de cinco décadas atrás, Jair Bolsonaro, recém-empossado, descreve as universidades usando a mesma estratégia discursiva:

\section{SD3}

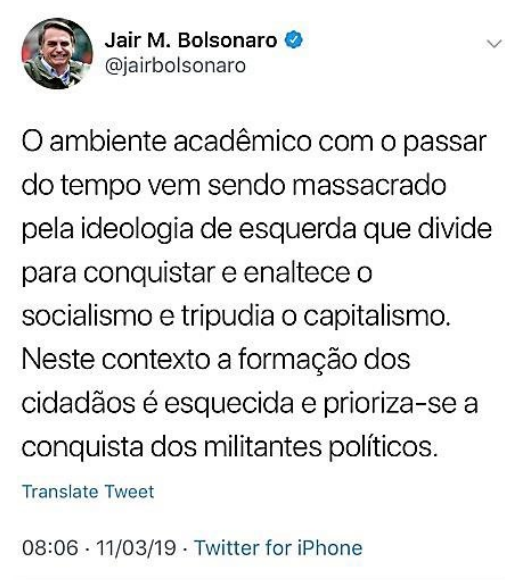

Fonte: Twitter (2019).

Com base em Courtine (2009, p. 104), para quem "toda produção discursiva que se efetua nas condições determinada de uma conjuntura movimenta - faz circular - formulações anteriores, já enunciadas", entendemos que a representação da universidade pública como um ambiente massacrado pela ideologia de esquerda que divide para conquistar e enaltece o socialismo e 
Um romance hiper-circuitado: 2019 não passa e o curto da tradição literária Júlia de Mello Silva Oliveira • Nair Renata Amâncio • Rejane Cristina Rocha

tripudia o capitalismo, nas palavras de Bolsonaro, busca apagar as contradições próprias do sistema vigente, que, se por um lado, precisa garantir uma maior exploração da classe trabalhadora a partir de reformas implementadas pelo Estado, por outro, necessita inculcar na massa a ideia de que o capitalismo é o único modo de produção viável, capaz de assegurar bem-estar à humanidade, lançando mão do aparelho repressor contra os opositores.

$\mathrm{Na}$ condição de espaço de pluralidade de ideias e de resistência ao autoritarismo, as universidades públicas representam uma ameaça aos interesses hegemônicos em períodos de forte crise democrática, sendo um dos principais alvos. As universidades, enquanto ambiente de formação, reflete e desenvolve as diferentes posições das questões postas pela sociedade, "expressando conteúdos de classes radicalmente distintos", ressalta Bertoldo (2017, p. 156).

Nesse sentido, nem a repressão militar nem as ameaças e ações do governo Bolsonaro em desfavor da educação pública, seguindo as diretrizes impostas pelo capital, impediram as manifestações em favor das universidades públicas. Nas duas SDs abaixo, vemos como essa resistência se fez presente nas ruas do Brasil em períodos separados por cinco décadas:

SD4 - Vestibulandos exigem + vagas (1968)

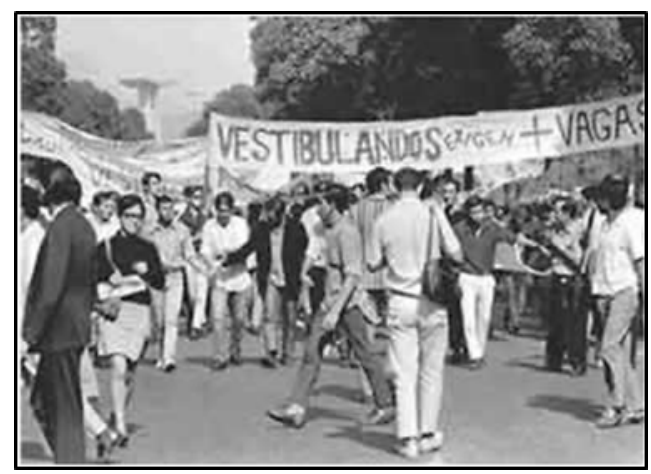

Fonte: http://www.une.org.br/home3/ubes_on-line/imgs/ historia_ubes_02_jpg.jpg (1968)
SD 5 - A universidade resiste (2019)

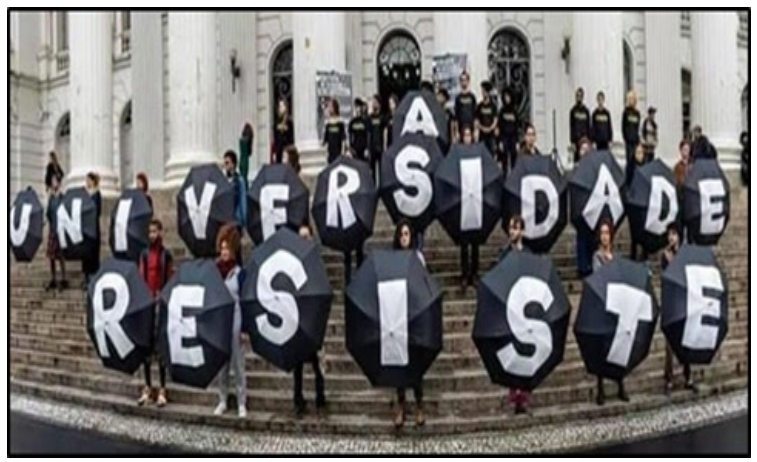

Fonte: Everson Bressan/Futura Pressa/Estadão (2019) 
Um romance hiper-circuitado: 2019 não passa e o curto da tradição literária Júlia de Mello Silva Oliveira • Nair Renata Amâncio • Rejane Cristina Rocha

De um lado, vemos a reivindicação de estudantes secundaristas por mais vagas nas universidades públicas em 1968. A manifestação, ocorrida na cidade do Rio de Janeiro, foi organizada pela União Brasileira dos Estudantes Secundaristas (Ubes). De outro, temos uma das manifestações realizadas ao longo de 2019 por estudantes do ensino básico e superior e por profissionais da educação para protestar contra os cortes no orçamento da educação e da pesquisa. Em 15 de maio, universitários se reuniram nas escadarias do prédio da Universidade Federal do Paraná com guardas-chuvas abertos com os dizeres A Universidade resiste.

As duas materialidades apontam para uma posição-sujeito que se contraidentifica com as ações dos governos de cada época, considerando as suas CPs estritas. Importante destacar que a contraidentificação ${ }^{4}$ se direciona para o processo de constituição da subjetividade de sujeitos que, embora voltem contra decisões do Estado, sofrem a determinação de um efeito de memória que os conduzem à identificação com a FD dominante (INDURSKY, 2008). Nesse sentido, as reivindicações dos sujeitos em análise, ora se movimentam no sentido de busca de ampliação de um quadro (+ vagas), ora para a manutenção de uma situação anterior.

Finalizando as nossas análises, reforçamos que a crise política advinda dos golpes de 1964 e 2016 foi e é uma ação surgida dos interesses hegemônicos. A sua discursividade, vale lembrar, é atualizada em momentos de forte crise do capital, que evidenciam os conflitos sociais, em vista de sua intensificação, aos quais o Estado responde com mais repressão para assegurar a manutenção de um modo de produção essencialmente excludente. Para isso, valem-se dos AIE para limitar e extinguir direitos, como o acesso às universidades públicas.

\footnotetext{
4 Em Semântica e discurso: uma crítica à afirmação do óbvio (2014), Pêcheux indica que o sujeito pode assumir três diferentes modalidades de subjetivação, ou posições-sujeito: de identificação com a ordem dominante, tornando-se um reprodutor de sua ideologia; de contraidentificação com essa ordem, através do distanciamento, do questionamento ou da dúvida, ao mesmo tempo em que sofre a sua determinação; e de desidentificação com a ideologia dominante, levando-o a se identificar com uma FD contra-hegemônica.
} 


\section{Breve conclusão}

Os objetivos do Estado em torno da educação, independente do seu modelo político, recaem na submissão dos sujeitos às imposições do sistema hegemônico. No entanto, como demonstramos ao longo deste estudo, esse controle é falho, o que reforça o entendimento de que as imposições do modo de produção vigente não se dão sem encontrar resistência.

Como consequência, quanto mais oposição se faz ao Estado, mais despótico este se torna para proteger os interesses capitalistas. Nessa direção, a universidade pública, enquanto espaço de pluralidade de sentidos, é um dos principais alvos dos governos tiranos ou simpatizantes destes, em virtude da histórica posição daquela em defesa da democracia, como aconteceu em plena ditadura militar (1964-1985) e no pós-golpe institucional de 2016.

Finalizando o artigo, esperamos que suas reflexões possam contribuir com as discussões sobre o papel do Estado na garantia de uma educação plena para os brasileiros, sobretudo para os mais vulneráveis, possibilitando o acesso a um ensino, acima de tudo, conscientizador.

\section{Referências}

ALMEIDA, Camila. Alvos de críticas e cortes, universidades lutam para mostrar sua importância. Revista Galileu, 2019. Disponível em: https:// revistagalileu.globo.com/Sociedade/noticia/2019/08/alvo-de-criticas-e-cortes-universidades-lutam-para-mostrar-sua-importancia.html. Acesso em: 12 maio 2020.

ALTHUSSER, Louis. Aparelhos ideológicos de Estado: nota sobre os aparelhos ideológicos de Estado (AIE). Tradução de Walter José Evangelista e Maria Laura Viveiros de Castro. 2. ed. Rio de Janeiro: Graal, 1985. 
ALVES, Márcio Moreira. Beabá dos MEC-USAID. Rio de Janeiro: Edições Gernasa, 1968.

AMARAL, Maria Virgínia Borges. Discurso e relações de trabalho. Maceió: EDUFAL, 2005.

BERTOLDO, Edna. “Escola Livre" e "Sem Partido": a internalização da lógica do capital. In: NOMERIANO, Aline Soares et al. As políticas educacionais no contexto dos limites absolutos do Estado e do capital em crise. Maceió: Coletivo Veredas, 2017. P. 139-157.

COURTINE, Jean-Jacques. Análise do discurso político: o discurso comunista endereçado aos cristãos. Trad.: Patrícia Chittoni Ramos Reuillard. São Carlos/SP: EduFSCar, 2009.

CARVALHO, Alexandre Douglas Zaidan de. Entre o dever da toga e o apoio à farda: independência judicial e imparcialidade no STF durante o regime militar. Revista Brasileira de Ciências Sociais, São Paulo, v. 32, n. 94, p. 1-22, 2017. Disponível em: https://doi. org/10.17666/329415/2017. Acesso em: 21 maio 2020.

CAVALCANTE, Maria do Socorro de A. O. A língua sob o olhar da Análise do Discurso. In: MOURA, Denilda (org.). Os múltiplos usos da língua. Maceió: EDUFAL, 1999. P. 179-182.

DUARTE, Newton. Vigotski e o "aprender a aprender": crítica às apropriações neoliberais e pós-modernas da teoria vigotskiana. 4. ed. Campinas, SP: Autores Associados, 2006.

\section{DW. Batida policial em universidades acirra tensão pré-eleição.}

2018. Disponível em: encurtador.com.br/hjyRV Acesso em: 19 ago. 2021.

FGV. Centro de Pesquisa e Documentação de História Contemporânea do Brasil-CPDOC. Passeata dos cem mil. 2009. Disponível em: http:// www.fgv.br/cpdoc/acervo/dicionarios/verbete-tematico/passeata-dos-cem-mil. Acesso em: 26 maio 2020.

INDURSKY, Freda. Unicidade, desdobramento, fragmentação: a trajetória da noção de sujeito em Análise do Discurso. In: MITTMANN, Solange et al. Práticas discursivas e identitárias: sujeito e língua. Porto Alegre: Nova Prova, 2008. P. 9-33. 
MAGALHÃES, Belmira. A crise estrutural do capitalismo e o irracionalismo. Conexão Letras, Porto Alegre, v. 14, n. 22, p. 81-91, 2019.

MARIANI, Bethania. O PCB e a imprensa: os comunistas no imaginário dos jornais (1922-1989). Rio de Janeiro: Revan; Campinas, SP: UNICAMP, 1998.

MÉSZÁROS, István. Para além do capital: rumo a uma teoria da transição. Tradução de Paulo Cezar Castanheira e Sérgio Lessa. São Paulo: Boitempo, 2011.

ORLANDI, Eni. Discurso e leitura. 2 ed. Campinas, SP: Cortez; São Paulo: Editora da Universidade Estadual de Campinas, 1993.

ORLANDI, Eni. Interpretação. Autoria, leitura e efeitos do trabalho simbólico. 6 ed. Campinas/SP: Pontes Editores, 2012.

PÊCHEUX, Michel. O discurso: estrutura ou acontecimento. Tradução de Eni P. Orlandi. 5 ed. Campinas/SP: Pontes editores, 2008.

PÊCHEUX, Michel. Semântica e discurso: uma crítica à afirmação do óbvio. Tradução de Eni P. Orlandi. Campinas, SP: Ed. da Unicamp, 2014. PRONER, Carol et al. (org.). A resistência ao golpe de 2016. Bauru, SP: Clacso/Projeto Editorial Praxis, 2016.

SARTORI, Vitor Bartoletti. Lukács e a crítica ontológica ao direito. São Paulo: Cortez, 2010.

SILVA SOBRINHO, Helson. Os (des)arranjos das lutas entre posições idealistas e materialistas na Análise do Discurso. In: BALDINI, Lauro \& BARBOSA FILHO, Fábio. Análise de discurso e materialismos: prática política e materialidades. V. 2. Campinas-SP: Pontes, 2018.

STF. STF referenda liminar que garantiu livre manifestação de ideias em universidades. 2018. Disponível em: http://www.stf.jus.br/ portal/cms/verNoticiaDetalhe.asp?idConteudo=394447. Acesso em: 12 maio 2020. 